\title{
Editorial: Social Security in an Ageing World
}

\author{
Sarah Harper
}

Published online: 26 May 2010

(C) Springer Science+Business Media B.V. 2010

\section{JPA 2:1}

The first International Social Security Association (ISSA) European Regional Forum, which convened in Warsaw, Poland, in 2010, identified demographic change and the economic crisis as being the two broad common "threats" facing the ability to successfully provide social security for the citizens of Europe. The associated Development Trends Report, Dynamic Social Security for Europe: Choice and Responsibility, also placed population ageing as one of the major trends shaping and constraining the environment in which future European social security would have to be delivered. However, as the report points out, demographic trends cannot be understood in isolation but require careful consideration of other competing trends which will also fight for space in the policy debates. Technological advances are encouraging individualised products and services, which pose a set of series challenges to social security policy makers and administrators as they balance appropriately regulated choices with protection against individual risk. Globalisation is posing the challenge of declining coverage and benefit adequacy, alongside the need for wider social security coverage. These all need to be set alongside the new challenge of the global financial and economic crisis which has significantly weakened Europe's economies. According to the IMF in 2009 (IMF 2009), the Euro zone was estimated to have contracted by $4.2 \%$, Central and Eastern European (CEE) Countries by $3.7 \%$, and the Independent States (CIS) countries, by $5.1 \%$. On top of this, the EU projections over the next 50 years forecast that population ageing will lead to a near 5\% increase in social expenditure per GDP within the current EU27. This will comprise a predicted increase in pension expenditure of $2.4 \%$, health care of $1.5 \%$ and long term care of $1.1 \%$, only slightly counteracted by a fall of $0.2 \%$ each in unemployment benefits and education (EC 2009).

This editorial draws on the address given to the ISSA Regional Conference, Warsaw, March 2010 (Harper 2010) 
The ISSA define Dynamic Social Security as "policies and processes geared to better ensure accessible and sustainable social protection systems that not only provide protection, encourage prevention, and support rehabilitation and (re)integration, but also contribute to better achieving socially inclusive and economically productive societies" (ISSA 2010). This then raises the question whether countries have the capacity to adapt in order to successfully achieve social inclusion and economic productivity in the light of the above mentioned challenges, and in particular population ageing.

Population ageing will clearly impact upon all social security provisions from health and long-term care, pensions, unemployment and disability provision, to family structures impacting on family benefits. Regardless of the demand, whether health or financial, the key challenge will be society's capacity to adapt to population ageing. This will include the capacity of individuals and households to make the relevant adjustments to savings behaviour, labour supply, private intergenerational transfers, and investment in human capital, and the capacity of institutions to make the relevant adjustments to facilitate these. However as societies attempt to successfully adjust to population ageing, a key public policy question is how national collective goals will influence these necessary societal adjustments, and how such required adjustments will be facilitated or restricted by existing social goals. Such goals include, for example, that of increasing general prosperity. Here there is fear that population ageing will reduce economic growth, and the policy challenge is to minimise this effect. Similarly, is the goal of maintaining fairness both within and between generations. An important factor here is the concept of intergenerational fairness and whether this will change in the light of the current population ageing. A key question for current ageing European populations, which have arisen through both fertility and mortality reduction is whether successful cohorts (in terms of both fertility and mortality reduction) pass on the cost of such success to future cohorts via the traditional intergenerational contract, or bear the cost of their success via an adapted intergenerational contract. This latter contract would require older cohorts to bear the costs of their longer lives through, for example, higher post-retirement contributions to their own welfare and/or a longer working life.

In terms of providing financial security, policy needs to set the framework of incentives within which individual and institutional decisions are made. Key consideration in the light of population ageing include the importance of integrating public and private transfers into future systems including understanding the complementary relationship between private and public intergenerational transfers, and the relationship between upward and downward transfers, and exploring frameworks to support and encourage individual responsibility. It may be argued, for example, that population ageing will necessitate a division between government responsibility to keep population out of poverty and individual responsibility to raise personal standards of living.

A second set of policy challenges arise though the provision of care. Howse (2010) clarifies the three main challenges that population ageing holds for the provision of health and social care: amount of ill health; type of ill health; ability to care. Population ageing will have a large and independent effect on the total amount of ill-health and disability in the population and as a result will exert pressure 
to increase total health care spending. As Howse argues, in order to understand the impact of population ageing on health care systems we must understand both the relationship between population ageing and the scale of health needs, and the relationship between increasing health care needs and levels of health care spending.

The relationship between population ageing and the scale of health needs arises because each individual who survives into later and later old age is likely to have more and more serious health problems than they did in former years. Thus, as societies improve their population life expectancy, so the proportion of the population with serious health problems will increase, unless there is a countervailing improvement in the health of successive birth cohorts which shows up as a decrease over time in age-specific prevalence rates. Similarly of course, if a larger proportion of the overall population falls within the age categories which are associated with a steep rise in the risk of disease and disability, then the average person in the general population will have more health problems to bring to the attention of the health care system.

The second relationship, between increasing health care needs and levels of health care spending, is mediated by a host of non-demographic factors, such as income, lifestyle characteristics, and new technology, alongside the effects of environmental factors, which are driving up the demand for new advanced medical applications. A further important consideration concerns the relative importance of age and remaining life expectancy or proximity to death, in determining the age profile of health care spending in the population as a whole. In conclusion, Howse argues that the predicted increases in medical and health care costs are therefore not the result of growing numbers of older people per se, but of current policy frameworks within which these costs will occur.

In addition population ageing will also change the kinds of health problem that people bring to the system, the shift from acute infectious disease to complex chronic long term ill-health and disability, the chronic disease burden, and as a result will exert pressure for a major shift in the allocation of health care resources and the configuration of services. Furthermore, changing dependency ratios will make it harder for ageing societies to provide for the care of their older members. The challenge is likely to be compounded in countries where population ageing is associated with an absolute decline in the working age population, since this will have an adverse effect on the resources available to the health care system.

Given the complex interactions which will arise from population ageing alone, let alone from the other identified challenges, the ISSA is thus to be commended on its determination to coordinate future efforts with an array of other players. Social security issues cannot be tackled in isolation, they require shared and complimentary approaches with others working in the areas of health, labour markets and family. The ISSA also recognises the need for enhanced knowledge which can be widely shared in a supportive manner.

Future policy lessons in the light of population ageing will by necessity have to be holistic and focus around the development of broad, coherent and integrated multi-pillar approaches to labour markets, social security and health and social care. These should enable and promote longer working lives through life long training, education and skills updating, and the provision of appropriate working environments for older workers; ensure that private family/household transfers are integrated 
into old age security systems where possible; promote wellbeing and enable healthy active living to reduce chronic illness and health care costs and support active contributory life for as long as possible; and provide access to education across the life course to ensure that all individuals are prepared physically, mentally, socially and financially to cope with increasing individual responsibility for old age.

\section{References}

EC. (2009). The 2009 Ageing Report: Economic and budgetary projections for the EU-27 member states (2008-2060). Brussels: European Commission DGEFA.

Harper, S. (2010). Societal challenges and the capacity to adapt: Social Security in an ageing world. Address to ISSA Regional Meeting, Warsaw March 2010.

Howse, K. (2010). What kinds of policy challenge does population ageing generate for health systems? IARU Working Paper, Oxford.

IMF. (2009). Global economy contracts, with slow recovery next year. IMF April 2009.

ISSA. (2010). Dynamic Social Security for Europe: Choice and Responsibility ISSA Geneva, 2010. 